\title{
The influence of the EUV spectrum on plasma induced by EUV radiation in argon and hydrogen gas
}

\section{Citation for published version (APA):}

Van Der Horst, R. M., Osorio, E. A., Banine, V. Y., \& Beckers, J. (2016). The influence of the EUV spectrum on plasma induced by EUV radiation in argon and hydrogen gas. Plasma Sources Science and Technology, 25(1), [015012]. https://doi.org/10.1088/0963-0252/25/1/015012

\section{Document license:}

TAVERNE

DOI:

10.1088/0963-0252/25/1/015012

Document status and date:

Published: 01/02/2016

\section{Document Version:}

Publisher's PDF, also known as Version of Record (includes final page, issue and volume numbers)

\section{Please check the document version of this publication:}

- A submitted manuscript is the version of the article upon submission and before peer-review. There can be important differences between the submitted version and the official published version of record. People interested in the research are advised to contact the author for the final version of the publication, or visit the $\mathrm{DOI}$ to the publisher's website.

- The final author version and the galley proof are versions of the publication after peer review.

- The final published version features the final layout of the paper including the volume, issue and page numbers.

Link to publication

\section{General rights}

Copyright and moral rights for the publications made accessible in the public portal are retained by the authors and/or other copyright owners and it is a condition of accessing publications that users recognise and abide by the legal requirements associated with these rights.

- Users may download and print one copy of any publication from the public portal for the purpose of private study or research.

- You may not further distribute the material or use it for any profit-making activity or commercial gain

- You may freely distribute the URL identifying the publication in the public portal.

If the publication is distributed under the terms of Article 25fa of the Dutch Copyright Act, indicated by the "Taverne" license above, please follow below link for the End User Agreement:

www.tue.nl/taverne

Take down policy

If you believe that this document breaches copyright please contact us at:

openaccess@tue.nl

providing details and we will investigate your claim. 
The influence of the EUV spectrum on plasma induced by EUV radiation in argon and hydrogen gas

This content has been downloaded from IOPscience. Please scroll down to see the full text. 2016 Plasma Sources Sci. Technol. 25015012

(http://iopscience.iop.org/0963-0252/25/1/015012)

View the table of contents for this issue, or go to the journal homepage for more

Download details:

IP Address: 131.155.151.137

This content was downloaded on 19/01/2016 at 09:02

Please note that terms and conditions apply. 


\title{
The influence of the EUV spectrum on plasma induced by EUV radiation in argon and hydrogen gas
}

\author{
R M van der Horst ${ }^{1}$, E A Osorio ${ }^{2}$, V Y Banine ${ }^{1,2}$ and J Beckers ${ }^{1}$ \\ ${ }^{1}$ Department of Applied Physics, Eindhoven University of Technology, PO Box 513, 5600MB \\ Eindhoven, The Netherlands \\ 2 ASML The Netherlands B.V., PO Box 324, 5500AH Veldhoven, The Netherlands \\ E-mail: r.m.v.d.horst@tue.nl
}

Received 24 August 2015, revised 21 October 2015

Accepted for publication 12 November 2015

Published 16 December 2015

\begin{abstract}
Plasmas induced by EUV radiation are scarcely investigated, although they are unique since they are created without any discharge. These plasmas are also of interest from an applicational point of view, since they are related to the lifetime of optics in EUV lithography tools. In order to assess this impact, it is essential to characterize and understand EUV-induced plasma. In this contribution the influence of the background gas (argon and hydrogen) in the lithography tool and the spectrum of the illumination source on the electron density of EUVinduced plasma is investigated using microwave cavity resonance spectroscopy.

The experimental results showed that out-of-band radiation $(>20 \mathrm{~nm})$ is the main contributor to EUV-induced plasma in both argon and hydrogen. In hydrogen, this contribution is relatively more important than in argon due to the stronger wavelength dependence of the photoionization cross section of hydrogen than of argon. Furthermore, the production of electrons by out-of-band radiation lasts longer than the production by in-band radiation $(10-20 \mathrm{~nm})$ due to the longer temporal width of out-of-band radiation. Finally, the obtained results correspond reasonably well with estimates from a simplified absorption model.
\end{abstract}

Keywords: EUV, microwave cavity resonance spectroscopy, electron density, spectral influence

(Some figures may appear in colour only in the online journal)

\section{Introduction}

Plasmas are widely studied in various fields of research. Plasma induced by EUV radiation, however, is scarcely investigated, although it is a unique plasma since it is created without any discharge. This type of plasma also occurs in space [1-4]. EUV-induced plasma in the context of EUV lithography is the topic of this paper.

The semiconductor industry is continuously striving to reduce the size of computer chips in order to meet the demand of more computational power and memory capacity at lower cost and higher efficiency. Currently, further miniaturization is achieved by reducing the wavelength used in lithography tools from $192 \mathrm{~nm}$ to $13.5 \mathrm{~nm}$, the latter wavelength being equivalent to a photon energy of $92 \mathrm{eV}$. This lithography technique is called EUV lithography. In reality, however, the EUV beam is not monochromatic, i.e. the EUV source has a specific emission spectrum. In the past xenon-based EUV sources were used. However, since the power of xenon-based sources could not be sufficiently increased for commercial application, nowadays EUV sources based on tin are used. The absorption of EUV radiation by the low pressure background gas in the lithography tools generates a plasma due to photoionization, i.e. an EUV-induced plasma. This absorption, and hence the electron density of the EUV-induced plasma, is strongly dependent on the background gas and spectrum of the EUV radiation (see figure 1). The EUV-induced plasma influences the lifetime of the expensive and highly delicate 


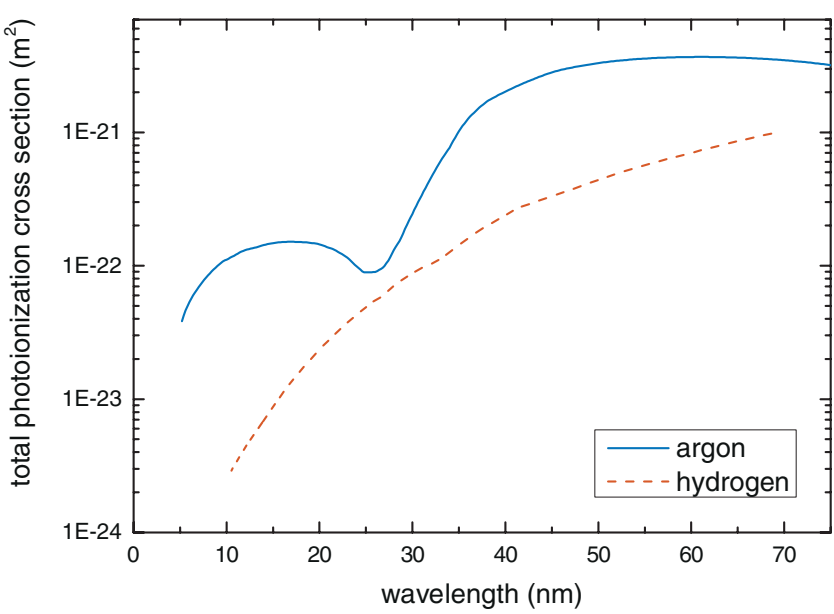

Figure 1. Total photoionization cross sections for both argon [9] and hydrogen [10-12].

optics in EUV lithography tools, this long term impact is a key interest for the semiconductor industry. Fundamental knowledge regarding EUV-induced plasma is essential to understand and assess the impact of EUV-induced plasma on the optics in lithography tools.

Recently, we were the first to report non-intrusive measurements of the electron density in EUV-induced argon plasmas using a technique known as microwave cavity resonance spectroscopy [5]. In later contributions, we studied the influence of the pressure and EUV pulse energy in EUV-induced plasma in argon [6] and hydrogen [7]. Moreover, in [8] it was shown that our experimentally obtained results are in good agreement with PIC-MC calculations.

The influence of the transition from xenon- to tin-based sources on EUV-induced plasma has not been investigated until now. In this contribution, both the influence of the background gas (argon or hydrogen) and the EUV spectrum on the electron density of EUV-induced plasma is studied. Argon and hydrogen are chosen since both gases are used in lithography tools. The effect of the EUV spectrum is studied by using two different EUV sources (xenon- and tin-based) and by using various optical transmission filters.

\section{Microwave cavity resonance spectroscopy}

The electron density is measured using a technique called microwave cavity resonance spectroscopy (MCRS) [13, 14]. This technique has been used previously in radio frequency (RF) plasmas [15-18], discharge tubes $[19,20]$ and recently in EUV-induced plasmas [5, 6]. The concept of MCRS is already extensively described in these publications, hence, we suffice with a brief description of MCRS. In MCRS measurements, a standing wave is excited in a (cylindrical) cavity. These standing waves can only be excited at specific frequencies, the resonant frequencies, which depend, amongst others, on the permittivity of the medium inside the cavity. When free electrons are generated inside the cavity (for instance due to photoionization of the gas inside), the permittivity changes and, hence, the resonant frequency shifts by $\Delta \omega$. From this $\Delta \omega$ the electron density can be determined as [6]:

$$
\bar{n}_{e}=\frac{2 m_{e} \varepsilon_{0}}{e^{2}} \frac{\omega^{2}}{\omega_{0}} \Delta \omega
$$

with $m_{e}$ the electron mass, $e$ the elementary charge and $\omega_{0}$ and $\omega$ the resonant frequencies without and with plasma, respectively. Note that this method gives the average electron density weighted with the square of the local electric field of the excited mode $\vec{E}(\vec{r})[18]$ :

$$
\bar{n}_{e}=\frac{\int_{\text {cavity }} n_{e}(\vec{r}) E^{2}(\vec{r}) \mathrm{d} \vec{r}}{\int_{\text {cavity }} E^{2}(\vec{r}) \mathrm{d} \vec{r}} .
$$

To determine the local electron density, the spatial profile on the electron density needs to be known. Since this profile is unknown, here we present the square-electric-field-weighted average electron density $\left(\bar{n}_{e}\right)$.

\section{Experimental set-up}

Two types of EUV sources have used in this work, a xenonbased and tin-based (laser assisted) discharge produced plasma source. The details of the overall set-up, both sources and the diagnostics are described in this section.

\subsection{Overall set-up}

Although different EUV sources have been used in this work, the general layout of the experimental set-up is very similar for all experiments (figure 2). The set-up consists of three chambers: the source, collector and measurement chamber. The source chamber contains either the xenonor tin-based EUV source. Details of these sources can be found in $[21,22]$; the spectra of both sources are given in figure 3 . The collector, which is a set of rotationally symmetric multi-shell grazing incidence mirrors located in the collector chamber, collects and focuses the radiation generated by the EUV source in the intermediate focus (IF) in the measurement chamber. The collector and measurement chamber are differentially pumped to allow high vacuum $\left(<10^{-4} \mathrm{~Pa}\right)$ in the measurement chamber. An SPF (spectrum purity filter) or aluminium filter can be installed in the beam path; the transmission curves of these filters is given in figure 4 . The pressure in the measurement chamber is controlled by a needle valve and stabilized with a feedback loop including the pump system. In all measurements presented here, the pressure was $5 \mathrm{~Pa}$.

\subsection{Measurement vessel}

The main diagnostic placed in the measurement vessel was microwave cavity resonance spectroscopy (MCRS). In case of the xenon-based source, the cavity is placed around IF, while in case of the tin-based source, the cavity is placed about $20 \mathrm{~cm}$ after IF for technical reasons; to ensure that the cavity walls were not illuminated by EUV radiation, an aperture was installed in front of the cavity in tin-based source only. The cavity is made of aluminium and has an inner radius of $33 \mathrm{~mm}$ 


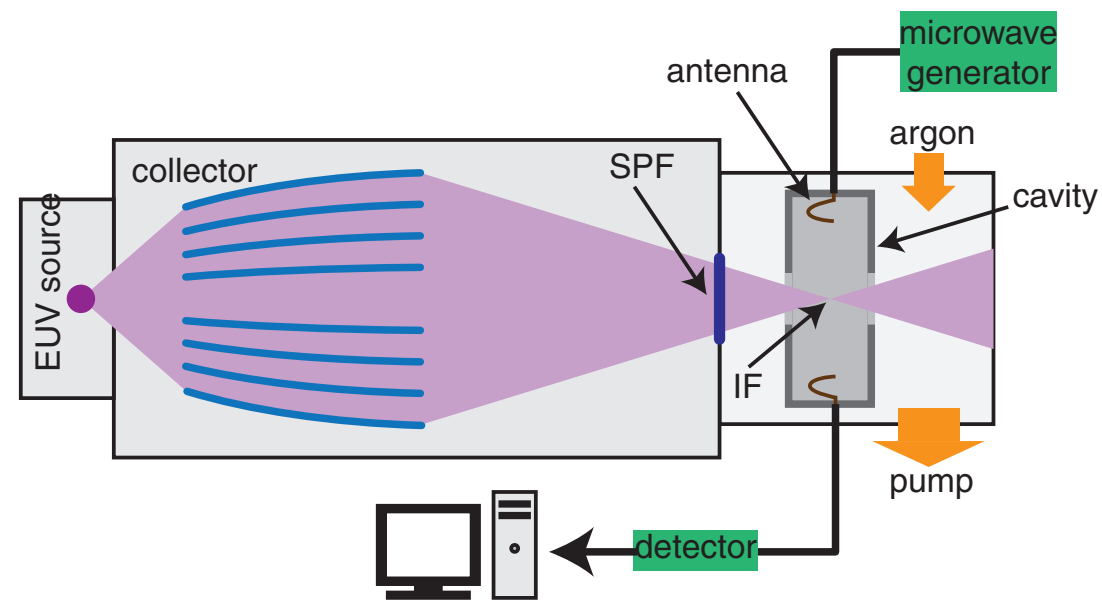

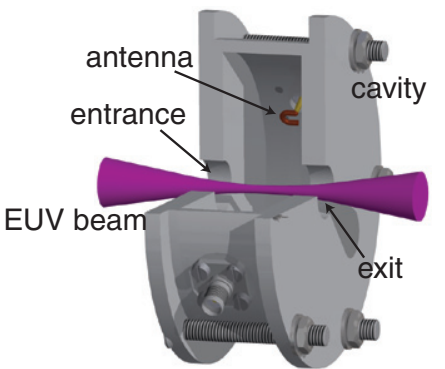

(b)

(a)

Figure 2. (a) Schematic drawing of the experimental set-up. The EUV radiation is created in the source chamber by either a xenon- or tin-based EUV source. The radiation is collected by a set of grazing incidence mirrors and focused in the measurement chamber. An SPF or aluminium filter can be installed in the beam path, the transmission curves are given in figure 3 . The argon or hydrogen pressure in the measurement chamber is varied with a needle valve. This figure is reproduced from [6], copyright 2015 IOP Publishing. (b) Drawing of the microwave cavity with an indication of the EUV beam. This figure is reproduced from [5], copyright 2014 IOP Publishing.

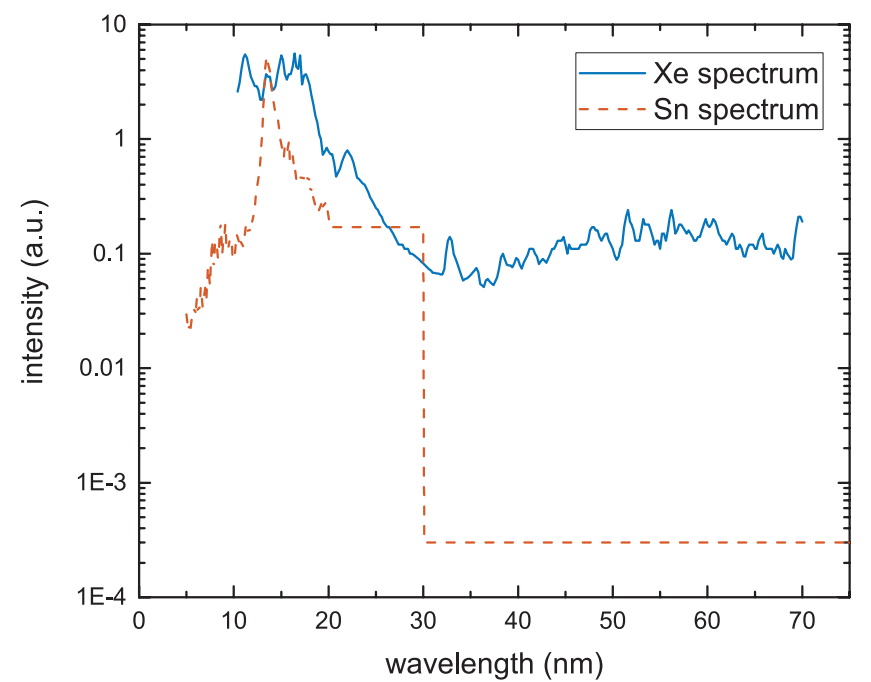

Figure 3. Relative spectra of the xenon- and tin-based EUV source [21, 23-25]. The xenon spectrum was measured with a LSP-VUV13S-M from ISAN by Kieft [24]. For the tin-based source, between 5-20 nm the spectrum has been measured with a spectrometer. Above $20 \mathrm{~nm}$ photodiodes with different transmission coatings have been used to measure the energy in specific wavelength ranges, which is depicted by the horizontal lines above $20 \mathrm{~nm}$.

and an inner height of $20 \mathrm{~mm}$. In order for the EUV beam to go through the cavity, a hole with a diameter of $13 \mathrm{~mm}$ is drilled in the top and bottom plate of the cavity. Two copper antennas are placed at opposite sides in the side-wall of the cavity; these antennas are not subject to EUV irradiation. One of these antennas is connected to a low power $(10 \mathrm{~mW})$ microwave generator (Stanford Research Systems SG386), exciting the $\mathrm{TM}_{010}$-mode around $3.5 \mathrm{GHz}$ in the resonant cavity. The electric field of this mode is calculated using the plasimo platform [26, 27] and is shown in figure 5. This electric field has its maximum value at the axis of the cavity, meaning that the electron density is most effectively sampled in the centre of

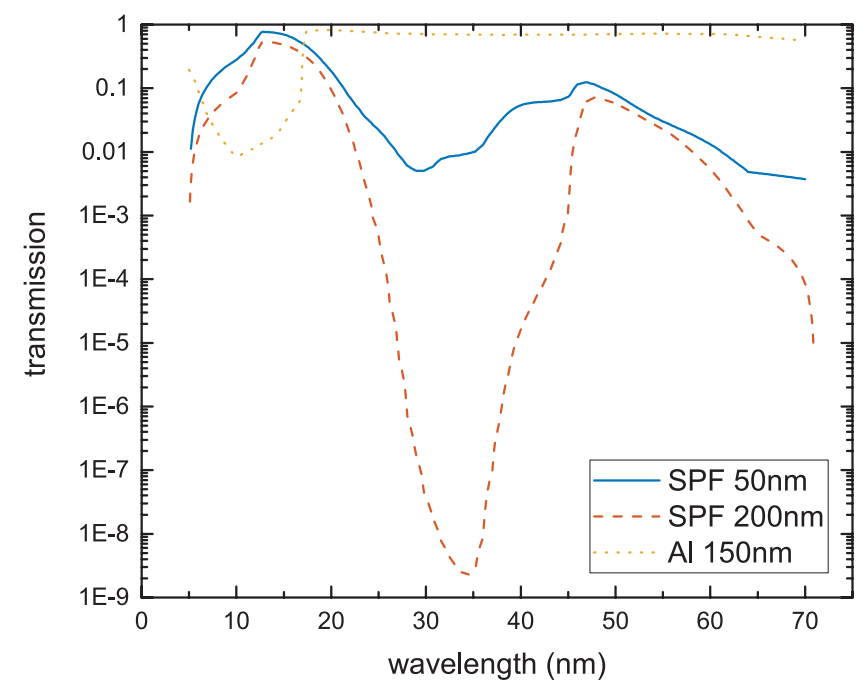

Figure 4. The transmission curves of the SPF and aluminium filters. The $50 \mathrm{~nm}$ SPF has been used in the xenon-based source, while the $200 \mathrm{~nm}$ SPF has been used in the tin-based source.

the cavity (see equation (2)), which is also the radial position at which the EUV beam is directed through the cavity. The other antenna is connected to a microwave detector (Hittite 602LP4E), which has a time response of $10 \mathrm{~ns}$, while the response time of the cavity is $14 \mathrm{~ns}$. The resonant frequency is determined by sweeping the frequency of the microwave generator over a predefined range and measuring the response of the cavity as a function of time. At every point in time, the response of the cavity as a function of frequency is fitted with a Fourier series (two components). The resonant frequency is the frequency where the fit has its maximum. In [5] it has been shown that the response time of the entire detection system is about $17 \mathrm{~ns}$. The error in the square-electric-field-weighted average electron density is less than $30 \%$ and the detection limit is $2 \times 10^{12} \mathrm{~m}^{-3}$ [5]. 


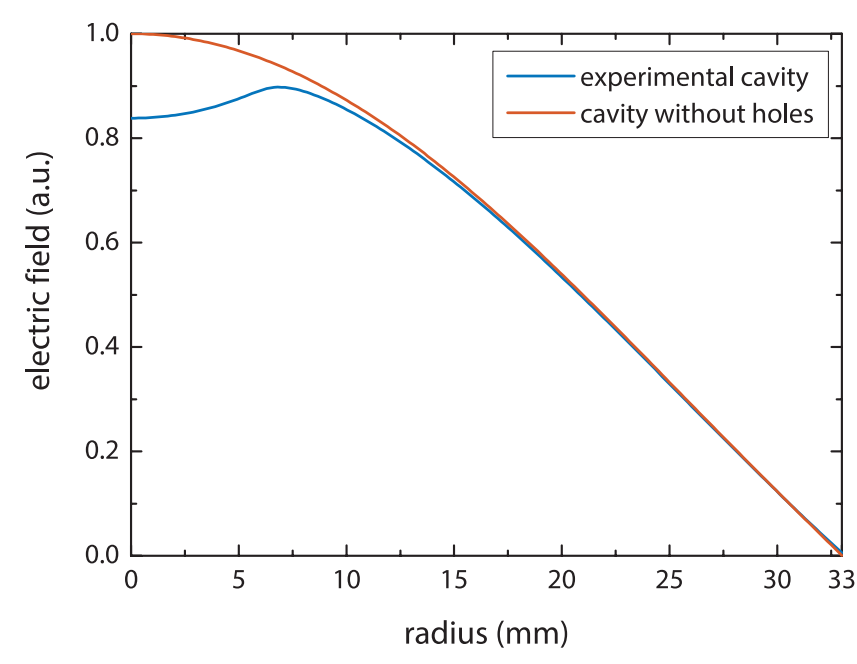

Figure 5. Modelled electric field of the $\mathrm{TM}_{010}$-mode in the cavity. The electric field is calculated with the plasimo platform [26, 27]. Moreover, the electric field of an ideal cavity without holes is shown. This graph is reproduced from [6], copyright 2015 IOP Publishing.

Furthermore, the EUV power is measured with either a temperature sensor in the xenon-base source or the FFST (far field screening tool) in the tin-based source. The power measurement based on the temperature sensor is extensively described in [6]; in this case the power is determined separately for all used filters. The FFST is developed by Xtreme Technologies $\mathrm{GmbH}$ to measure the EUV power. At the entrance of the FFST a zirconium filter is installed, which only transmits between 10 and $20 \mathrm{~nm}$. After this filter, a YAG crystal convert the EUV radiation to visible radiation, which is captured by a CCD camera. The intensity of the images recorded by the CCD camera is proportional to the EUV power. To obtain the absolute EUV power, the FFST has been calibrated at a synchrotron facility. The FFST measures the in-band EUV energy; to obtain the total EUV energy (in-band and out-of-band), the in-band EUV energy is extrapolated using the tin spectrum in figure 3 . The transmission curves of the filters (figure 4) is used to calculate the effect of the filters on the EUV energy.

\section{Results and discussion}

The influence of the EUV spectrum on the maximum squareelectric-field-weighted average electron density of the EUVinduced plasma in both argon and hydrogen gas was studied using various transmission filters in both a xenon-based and tin-based source.

\subsection{Argon gas}

4.1.1. Xenon-based source. The measured maximum $\bar{n}_{e}$ generated by the xenon-based source with different filters is given in table 1 . If a filter is placed in the beam path, the induced maximum $\bar{n}_{e}$ is lower since part of the spectrum is blocked by the filter. Although the spectrally integrated EUV pulse energy with the aluminium filter is a factor $11.0 \pm 0.8$ lower than the EUV pulse energy without filter, the maximum $\bar{n}_{e}$ is
Table 1. Measured and estimated maximum $\bar{n}_{e}$ in $5 \mathrm{~Pa}$ argon plasma generated by a xenon-based EUV source.

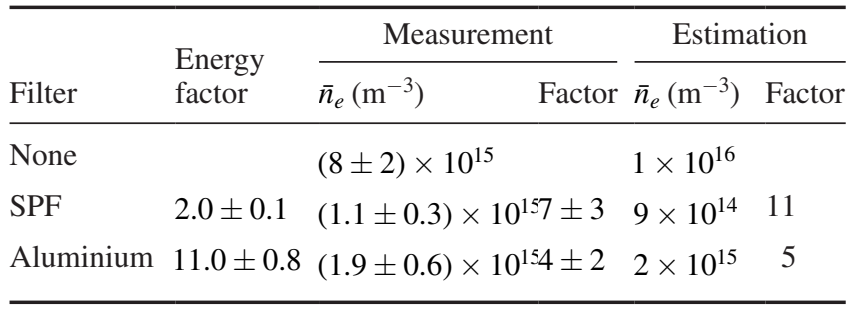

only a factor $4 \pm 2$ lower. This is because the photoionization cross section in the $20-70 \mathrm{~nm}$ band is much higher than in the $10-20 \mathrm{~nm}$ band. The importance of the $20-70 \mathrm{~nm}$ band also explains why $\bar{n}_{e}$ decreases by a factor $7 \pm 3$ due to the SPF (which blocks the 20-70 nm band), while the spectrally integrated EUV pulse energy only decreases by a factor $2.0 \pm 0.1$.

The influence of the filters on photoionization of the gas in the cavity can also be estimated with the applied EUV spectrum and the wavelength dependent photoabsorption cross section, which is extensively described in [6]. As discussed in this reference, the maximum $\bar{n}_{e}$ due to photoionization $n_{e}^{\max \text {,pi }}$ is given by:

$$
n_{e}^{\max , \mathrm{pi}}=p \int_{0}^{\infty} \frac{1.2 \sigma_{\mathrm{pi}}(\lambda) E_{\mathrm{EUV}}(\lambda)}{k_{\mathrm{B}} T_{g} A_{\mathrm{EUV}} h c / \lambda} \mathrm{d} \lambda,
$$

with $p$ the pressure, $\sigma_{\mathrm{pi}}$ is the photoionization cross section (see figure 1), $E_{\mathrm{EUV}}(\lambda)$ is the wavelength $\lambda$ dependent EUV pulse energy, $k_{\mathrm{B}}$ is Boltzmann's constant, $T_{g}$ is the gas temperature, $A_{\mathrm{EUV}}$ is the EUV beam cross section $\left(13 \mathrm{~mm}^{2}\right), h$ is Planck's constant and $c$ is the speed of light. The wavelength dependent EUV pulse energy is obtained by calibrating the relative spectrum (figure 3 ) with a wavelength integrated energy measurement, i.e. the relative spectrum is integrated over the wavelength and divided by the integrated EUV energy, which yields a calibration factor to convert the relative spectral intensity to an absolute energy scale. Using equation (2), the estimated electron density, which is valid in the centre of the cavity, is converted to an estimated $\bar{n}_{e}$, assuming the spatial distribution of the electron density is a square with a width equal to the FWHM of the EUV beam $(2 \mathrm{~mm})$. The results are also listed in table 1 and show very good correspondence with the measurements. This means that the calculations can be used to estimate the contributions of various bands of EUV radiation to the electron density (table 2). This table clearly shows that out-of-band radiation has a significant influence on $\bar{n}_{e}$ of EUV-induced plasma. While only $17 \%$ of the EUV pulse energy is in the 20-70 nm-band, it contributes to $91 \%$ of the created electrons. In this band, radiation above $50 \mathrm{~nm}$ is most important for photoionization. This can also be seen from figure 1; the photoionization cross section is more than 20 times higher above $50 \mathrm{~nm}$ than below.

4.1.2. Tin-based source. The measured maximum $\bar{n}_{e}$ generated by a tin-based source with different filters is given in table 3. By applying an SPF the density decreases by a factor $3 \pm 1$, while the EUV pulse energy decreases by a factor 2.3. The aluminium filter decreases the EUV pulse energy with 
Table 2. Contribution to the total maximum electron density in argon for different bands of EUV radiation in a xenon-based source.

\begin{tabular}{lll}
\hline Range $(\mathrm{nm})$ & Energy fraction $(\%)$ & $\begin{array}{l}\text { Contribution } \\
\text { to } n_{e}(\%)\end{array}$ \\
\hline $10-20$ & 83 & 9 \\
$13.4-13.6$ & 2 & 0.2 \\
$20-30$ & 6 & 1 \\
$30-40$ & 2 & 4 \\
$40-50$ & 3 & 18 \\
$50-60$ & 3 & 35 \\
$60-70$ & 3 & 32 \\
\hline
\end{tabular}

Table 3. Measured and estimated maximum square-electric-field weighted average electron density in $5 \mathrm{~Pa}$ argon generated by a tin-based EUV source.

\begin{tabular}{|c|c|c|c|c|c|}
\hline \multirow[b]{2}{*}{ Filter } & \multirow{2}{*}{$\begin{array}{l}\text { Energy } \\
\text { factor }\end{array}$} & \multicolumn{2}{|c|}{ Measurement } & \multicolumn{2}{|c|}{ Estimation } \\
\hline & & $\bar{n}_{e}\left(\mathrm{~m}^{-3}\right)$ & Factor & $\bar{n}_{e}\left(\mathrm{~m}^{-3}\right)$ & Factor \\
\hline None & & $(2.5 \pm 0.8) \times 10^{1}$ & & $8 \times 10^{15}$ & \\
\hline SPF & 2.3 & $(8.6 \pm 3) \times 10^{14}$ & $3 \pm 1$ & $3 \times 10^{15}$ & 3 \\
\hline Aluminium & 7.7 & $(4.4 \pm 1) \times 10^{14}$ & $6 \pm 2$ & $1 \times 10^{15}$ & 6 \\
\hline
\end{tabular}

a factor 7.7, while the decrease in $\bar{n}_{e}$ is a factor $6 \pm 2$. This seems to contradict with the observations in measurements using the xenon-based source. However, there is a significant difference in the emitted spectrum by the xenon-and tin-based sources.

For the tin-based source $\bar{n}_{e}$ can also be estimated from the spectrum and absorption cross section as described in the previous paragraph. In this case the spectrum of the tin source was used (figure 3). In order to obtain the spectrum of the radiation entering the cavity, the spectrum of the light generated by the source is multiplied by the transmission of the collector and the transmission of the argon gas between the source and the cavity (about $3 \mathrm{~m}$ ). The resulting spectrum is calibrated with a wavelength integrated energy measurement of the EUV source. If a filter is placed in the beam path, the spectrum is also multiplied with its transmission. The EUV beam has a radius of $6.4 \mathrm{~mm}$ in the centre of the cavity. Using equation (2), the estimated maximum electron density is converted to the maximum $\bar{n}_{e}$. To this end, it is assumed that the spatial distribution of the electron density is a square with a width equal to the diameter of the EUV beam. The estimated $\bar{n}_{e}$ is about a factor 3 larger than the measured $\bar{n}_{e}$. However, the estimated $\bar{n}_{e}$ difference due to the filters corresponds to the measured factors. Hence, the difference between the estimated and measured $\bar{n}_{e}$, is probably caused by an error in the EUV pulse energy estimation or due to the conversion from maximum electron densities to maximum $\bar{n}_{e}$. This means that also for this source, the calculations can be used to estimate the relative contributions of various bands of EUV radiation (table 4). The 20-70 nm-band radiation only contributes to $10 \%$ of the EUV-induced plasma, while the $10-20 \mathrm{~nm}$ band generates $90 \%$ of the plasma. In the previous section it was shown that the radiation above $50 \mathrm{~nm}$ is the most important source for photoionization. Since in the tin-based EUV source radiation above $30 \mathrm{~nm}$ is very small, also the photoionization
Table 4. Contribution to the total maximum electron density in argon for different bands of EUV radiation in a tin-based source.

\begin{tabular}{lll}
\hline Range $(\mathrm{nm})$ & Energy fraction $(\%)$ & $\begin{array}{l}\text { Contribution } \\
\text { to } n_{e}(\%)\end{array}$ \\
\hline $10-20$ & 94 & 90 \\
$13.4-13.6$ & 9 & 14 \\
$20-30$ & 4 & 9 \\
$30-40$ & 0.02 & 0.2 \\
$40-50$ & 0.002 & 0.2 \\
$50-60$ & 0.002 & 0.3 \\
$60-70$ & 0.002 & 0.3 \\
\hline
\end{tabular}

Table 5. Measured and estimated maximum square-electric-fieldweighted average electron density in $5 \mathrm{~Pa}$ hydrogen using a xenon-based EUV source.

\begin{tabular}{|c|c|c|c|c|c|}
\hline \multirow[b]{2}{*}{ Filter } & \multirow{2}{*}{$\begin{array}{l}\text { Energy } \\
\text { factor }\end{array}$} & \multicolumn{2}{|c|}{ Measurement } & \multicolumn{2}{|c|}{ Estimation } \\
\hline & & $\bar{n}_{e}\left(\mathrm{~m}^{-3}\right)$ & Factor & $\bar{n}_{e}\left(\mathrm{~m}^{-3}\right)$ & Factor \\
\hline None & & $(1.2 \pm 0$. & $10^{15}$ & $2 \times 10^{15}$ & \\
\hline SPF & $2.0 \pm 0.1$ & $(4.7 \pm 1)$ & $27 \pm 12$ & $7 \times 10^{13}$ & 21 \\
\hline Aluminium & $11.0 \pm 0.8$ & $(3.3 \pm 1)$ & $44 \pm 2$ & $3 \times 10^{14}$ & 4 \\
\hline
\end{tabular}

from this part of the spectrum is very small. For this reason, the photoionization is dominant in the $10-20 \mathrm{~nm}$ band, which also contains most of the EUV pulse energy (94\%).

\subsection{Hydrogen gas}

4.2.1. Xenon-based source. The measured maximum $\bar{n}_{e}$ in an EUV-induced hydrogen plasma using a xenon-based source with different filters (SPF and aluminium) are given in table 5. The EUV pulse energy at the entrance of the cavity is a factor $11.0 \pm 0.8$ lower if an aluminium filter (transmission between $20-70 \mathrm{~nm}$ ) is placed in the beam path. However, since the photoionization cross section is higher in the $20-70 \mathrm{~nm}$ band than in the $10-20 \mathrm{~nm}$ band, $\bar{n}_{e}$ is only a factor $4 \pm 2$ lower. This also explains why $\bar{n}_{e}$ decreases with a factor $27 \pm 12$ if an SPF (transmission between 10 and $20 \mathrm{~nm}$ ) is used, while the EUV pulse energy only decreases by a factor $2.0 \pm 0.1$.

The influence of the different filters on the measured $\bar{n}_{e}$ can also be estimated theoretically from the filtered EUV spectrum and the photoionization cross section as discussed in [7] and the previous section:

$$
n_{e}^{\max , \mathrm{pi}}=p \int_{0}^{\infty} \frac{1.05 \sigma_{\mathrm{pi}}(\lambda) E_{\mathrm{EUV}}(\lambda)}{k_{\mathrm{B}} T_{g} A_{\mathrm{EUv}} h c / \lambda} \mathrm{d} \lambda .
$$

The relevant estimates are also listed in table 5 and they correspond very well with the measurements. These calculations can thus be used to estimate the contributions of various EUV bands to $\bar{n}_{e}$ (see table 6). Just as in the case of argon, the $20-70 \mathrm{~nm}$ band is most important for the initial generation of plasma (96\%) while most energy is within the $10-20 \mathrm{~nm}$ band.

Furthermore, the temporal evolution of the creation of EUVinduced plasma is affected by the various filters (figure 6). When an SPF is placed in the beam path, the maximum $\bar{n}_{e}$ is reached earlier than without any filter or with an aluminium 
Table 6. Contribution to the total maximum $\bar{n}_{e}$ in hydrogen for different bands of EUV radiation using a xenon-based source.

\begin{tabular}{lll}
\hline Range $(\mathrm{nm})$ & Energy fraction $(\%)$ & $\begin{array}{l}\text { Contribution } \\
\text { to } \bar{n}_{e}(\%)\end{array}$ \\
\hline $10-20$ & 83 & 4 \\
$13.4-13.6$ & 2 & 0.5 \\
$20-30$ & 6 & 2 \\
$30-40$ & 2 & 3 \\
$40-50$ & 3 & 13 \\
$50-60$ & 3 & 34 \\
$60-70$ & 3 & 44 \\
\hline
\end{tabular}

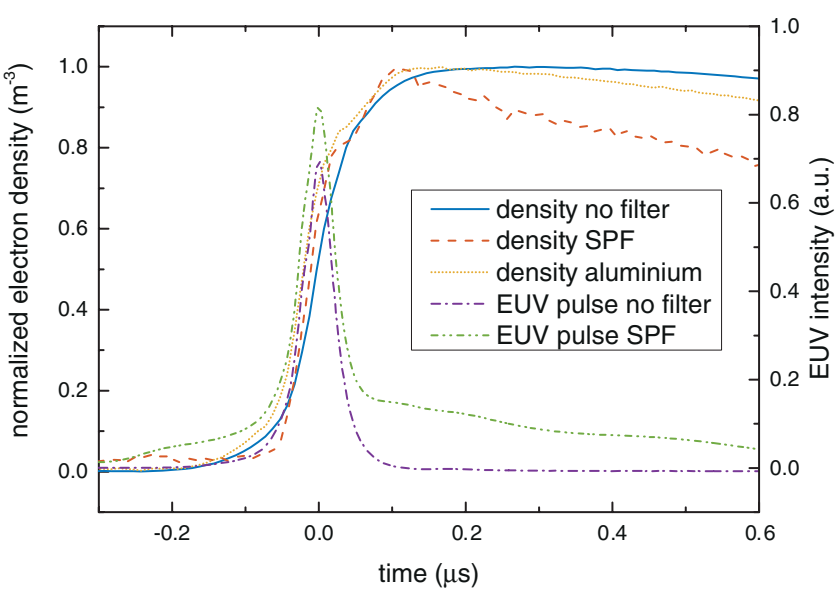

Figure 6. Normalized $\bar{n}_{e}$ as a function of time during the EUV pulse for various filters. The EUV pulse with and without an SPF is plotted for reference.

filter. This is caused by the difference in temporal evolution of the EUV spectrum. The various bands of the EUV spectrum have a different temporal width. The temporal width of the EUV pulse filtered with an SPF is shorter than without any filter (figure 6), i.e. the $10-20 \mathrm{~nm}$ band has a shorter temporal width than the $20-70 \mathrm{~nm}$ band. This is why the production of electrons due to photoionization lasts longer without any filter or with an aluminium filter; hence, the maximum $\bar{n}_{e}$ is reached later.

4.2.2. Tin-based source. The measured maximum $\bar{n}_{e}$ in an EUV-induced plasma in hydrogen using a tin-based source with an SPF and aluminium filter are given in table 7 along with the theoretical predictions based on the applied EUV spectrum and photoionization cross section. The effect of the filters on the electron density is captured well by the theoretical estimation. Hence, these calculations can be used to estimate the contribution of various bands of the EUV spectrum to the total $\bar{n}_{e}$ (table 8 ). The $10-30 \mathrm{~nm}$ band contributes to $96 \%$ of $\bar{n}_{e}$. In this band, most of the EUV pulse energy is in the $10-20 \mathrm{~nm}$ range. However, the $4 \%$ of EUV pulse energy which is in the $20-30 \mathrm{~nm}$ range still contributes $41 \%$ of $\bar{n}_{e}$. This is because the higher photoionization cross section compensates for the lower EUV pulse energy in the 20-30 nm band. This means that by controlling the spectrum of the EUV source, the plasma density can also be controlled.
Table 7. Measured and estimated maximum square-electric-fieldweighted average electron density in $5 \mathrm{~Pa}$ hydrogen using a tinbased EUV source.

\begin{tabular}{|c|c|c|c|c|c|}
\hline \multirow[b]{2}{*}{ Filter } & \multirow{2}{*}{$\begin{array}{l}\text { Energy } \\
\text { factor }\end{array}$} & \multicolumn{2}{|c|}{ Measurement } & \multicolumn{2}{|c|}{ Estimation } \\
\hline & & $\bar{n}_{e}\left(\mathrm{~m}^{-3}\right)$ & Factor & $\bar{n}_{e}\left(\mathrm{~m}^{-3}\right)$ & Factor \\
\hline None & & $(3.1 \pm 0.9) \times 10$ & & $1 \times 10^{15}$ & \\
\hline SPF & 2.3 & $(5 \pm 2) \times 10^{13}$ & $6 \pm 2$ & $3 \times 10^{14}$ & 4 \\
\hline Aluminium & 7.7 & $(9 \pm 3) \times 10^{13}$ & $3 \pm 1$ & $5 \times 10^{14}$ & 2 \\
\hline
\end{tabular}

Table 8. Contribution to the total maximum $\bar{n}_{e}$ in a hydrogen EUVinduced plasma for different bands of EUV radiation using a tinbased source.

\begin{tabular}{lll}
\hline Range $(\mathrm{nm})$ & Energy fraction $(\%)$ & Contribution to $\bar{n}_{e}(\%)$ \\
\hline $10-20$ & 94 & 55 \\
$13.4-13.6$ & 9 & 6 \\
$20-30$ & 4 & 41 \\
$30-40$ & 0.02 & 0.6 \\
$40-50$ & 0.002 & 0.5 \\
$50-60$ & 0.002 & 1 \\
$60-70$ & 0.002 & 1 \\
\hline
\end{tabular}

If the spectral influence in a hydrogen EUV-induced plasma is compared with an argon EUV-induced plasma, some significant differences can be observed. The 20-30 nm-band is more important for generation of electrons in hydrogen $(41 \%)$ than it is in argon (9\%). This is because the photoionization cross section of hydrogen depends more strongly on the wavelength than the photoionization cross section of argon (figure 1). As a result, the 20-30 nm-band has a larger contribution to $\bar{n}_{e}$ in hydrogen than in argon. The effect of electron impact ionization is too small to explain this difference $[6,7]$. Furthermore, the dependence of the electron impact ionization cross section on the electron energy is alike in argon and hydrogen [28, 29].

\subsection{Comparison of the Xe- and Sn-based source}

The main difference between the xenon- and tin-based EUV source is the generated spectrum. In short, the xenon-based source contains significantly more radiation above $20 \mathrm{~nm}$ than the tin-based source. Since the photoionization cross section for this part of the spectrum is higher, the EUV-induced plasma will be more dense even while the total EUV pulse energy is the same. This means that not only the total EUV pulse energy is important for creation of EUV-induced plasma, but even more the spectrum of the source. Since the radiation above $50 \mathrm{~nm}$ is most important for photoionization, $\bar{n}_{e}$ of the EUV-induced plasma is reduced drastically by reducing outof-band radiation.

A significant difference in the decay of EUV-induced plasma generated by a xenon- or tin-based EUV source was observed. Although it has not been verified yet, it should be pointed out that the gas flows in the two systems might be different, which could influence the decay. 


\section{Conclusions}

In this contribution, the influence of the EUV spectrum on a pulsed EUV-induced plasma in argon and hydrogen is studied. It was found that out-of-band radiation $(>20 \mathrm{~nm})$ is the main contributor to EUV-induced plasma. In-band radiation $(10-20 \mathrm{~nm})$ is less significant. In hydrogen, out-of-band contribution is relatively more important than in argon due to stronger wavelength dependence of the photoionization cross section of hydrogen than of argon. Due to the larger temporal width of out-of-band radiation, the production of electrons lasts longer due to out-of-band radiation than due to in-band radiation. Furthermore, a simplified absorption model can be used to obtain reasonable estimates of the electron density.

\section{Acknowledgments}

The authors would like to acknowledge ASML for their financial support and the opportunity to use its EUV sources.

\section{References}

[1] Bartnik A, Fedosejevs R, Wachulak P, Fiedorowicz H, Serbanescu C, Saiz E, Riley D, Toleikis S and Neely D 2013 Laser Part. Beams 31 195-201

[2] Bartnik A, Wachulak P, Fiedorowicz H, Jarocki R, Kostecki J and Szczurek M 2013 Radiat. Phys. Chem. 93 9-13

[3] Bartnik A, Fiedorowicz H and Wachulak P 2014 Phys. Plasmas 21073303

[4] Bartnik A, Wachulak P, Fiedorowicz H, Fok T, Jarocki R and Szczurek M 2014 Phys. Scr. T 161014061

[5] van der Horst R M, Beckers J, Nijdam S and Kroesen G M W 2014 J. Phys. D: Appl. Phys. 47302001

[6] van der Horst R M, Beckers J, Osorio E A and Banine V Y 2015 J. Phys. D: Appl. Phys. 48285203

[7] van der Horst R et al 2015 Exploring the electron density in plasma induced by EUV radiation: I. Experimental study in hydrogen J. Phys. D: Appl. Phys. submitted
[8] Astakhov D et al 2015 in preparation

[9] Saito N and Suzuki I H 1992 Int. J. Mass Spectrom. Ion Process. 115 157-72

[10] Dujardin G, Besnard M, Hellner L and Malinovitch Y 1987 Phys. Rev. A 35 5012-9

[11] Kossmann H, Schwarzkopf O, Kammerling B, Braun W and Schmidt V 1989 J. Phys. B: At. Mol. Opt. Phys. 22 L411-4

[12] Chung Y M, Lee E M, Masuoka T and Samson J A R 1993 J. Chem. Phys. 99885

[13] Jackson J 1962 Classical Electrodynamics 3rd edn (New York: Wiley)

[14] Rose D J and Brown S C 1952 J. Appl. Phys. 23 1028-32

[15] Haverlag M, Kroesen G M W, Bisschops T H J and de Hoog F J 1991 Plasma Chem. Plasma Process. 11 357-70

[16] Beckers J, Stoffels W W and Kroesen G M W 2009 J. Phys. D: Appl. Phys. 42155206

[17] Stoffels E, Stoffels W, Vender D, Kando M, Kroesen G and de Hoog F 1995 Phys. Rev. E 51 2425-35

[18] van de Wetering F M J H, Beckers J and Kroesen G M W 2012 J. Phys. D: Appl. Phys. 45485205

[19] Gundermann S, Loffhagen D, Wagner H E and Winkler R 2001 Contrib. Plasma Phys. 41 45-60

[20] Agdur B and Enander B 1962 J. Appl. Phys. 33 575-81

[21] Bergmann K, Schriever G, Rosier O, Müller M, Neff W and Lebert R 1999 Appl. Opt. 385413

[22] Jonkers J 2006 Plasma Sources Sci. Technol. 15 S8-16

[23] Kieft E R 2005 Transient behavior of EUV emitting discharge plasmas: a study by optical methods $P h D$ Thesis Eindhoven University of Technology Eindhoven

[24] Kieft E R 2008 private communications with ASML research

[25] Bergmann K, Küpper F, Verbraak H and Jonkers J 2008 Out-of-band radiation \& particle emission Technical Report Philips \& Fraunhofer Institut Lasertechnik

[26] van Dijk J, Peerenboom K, Jimenez M, Mihailova D and van der Mullen J 2009 J. Phys. D: Appl. Phys. 42194012

[27] Jimenez-Diaz M 2011 Modelling of microwave induced plasmas $P h D$ Thesis Eindhoven University of Technology Eindhoven

[28] Phelps A V and Petrovic Z L 1999 Plasma Sources Sci. Technol. 8 R21-44

[29] Yoon J S, Song M Y, Han J M, Hwang S H, Chang W S, Lee B and Itikawa Y 2008 J. Phys. Chem. Ref. Data 37913 